\title{
Karakterisasi Ring Valuasi Diskrit
}

\author{
Dwi Mifta Mahanani \\ Departemen Matematika \\ Fakultas Matematika dan Ilmu Pengetahuan Alam \\ Universitas Brawijaya \\ mdwimifta@ub.ac.id.
}

\begin{abstract}
Abstrak
Definisi ring valuasi sangat erat kaitannya dengan pemetaan valuasi pada lapangan hasil bagi dari ring tersebut. Oleh karena itu, definisi ring valuasi diskrit jika dikaitkan dengan adanya pemetaan valuasi merupakan ring yang value groupnya isomorfik dengan himpunan bilangan bulat (Matsumura [2]). Akan tetapi Piotr, Askar [3] menyebutkan bahwa suatu ring merupakan ring valuasi diskrit jika memenuhi tiga kondisi tertentu. Makalah ini akan membahas ekivalensi dari dua definisi tersebut.

Kata kunci: pemetaan valuasi, ring valuasi diskrit, value group.
\end{abstract}

\begin{abstract}
Definition of valuation ring is closely related with the existence of valuation mapping on field of fraction of that ring. Therefore, the definition of discrete valuation ring is a ring which value group is isomorphic with a set of integers (Matsumura [2]). However, Piotr, Askar [3] state that a discrete valuation ring is a ring which satisfies certain three conditions. This paper discusses about the equivalence of those definitions.
\end{abstract}

Keywords: discrete valuation ring, valuation mapping, value group.

\section{Pendahuluan}

Seperti namanya, ring valuasi sangat erat kaitannya dengan adanya pemetaan valuasi. Pemetaan valuasi ini merupakan pemetaan yang didefinisikan pada suatu lapangan $K$ ke suatu grup komutatif terurut total $G$ yang diperluas menjadi $G \cup\{\infty\}$. Untuk lebih jelasnya, perhatikan penjelasan berikut.

Misalkan $G$ merupakan grup komutatif terhadap operasi penjumlahan yang di dalamnya juga didefinisikan relasi $\geq$. Untuk setiap $a, b, c \in G$ dengan $a \geq b$, berlaku bahwa $a+c \geq b+c$. Kemudian $G$ diperluas menjadi $G \cup\{\infty\}$ dengan pendefinisan sebagai berikut:

(1) untuk setiap $a \in G$, berlaku bahwa $\infty \geq a$ dan

(2) untuk setiap $a \in G$, berlaku bahwa $a+\infty=\infty=\infty+a$.

Definisi 1.1. Pemetaan valuasi $\nu: K \longrightarrow G \cup\{\infty\}$ pada lapangan $K$ merupakan suatu pemetaan yang memenuhi ketiga sifat berikut:

(1) nilai valuasi dari a sama dengan $\infty$ jika dan hanya jika $a=0$,

(2) untuk setiap $x, y \in K$, berlaku bahwa $\nu(x y)=\nu(x)+\nu(y)$, dan

(3) untuk setiap $x, y \in K$, berlaku bahwa $\nu(x+y) \geq \min \{\nu(x), \nu(y)\}$.

2000 Mathematics Subject Classification: $05 \mathrm{C} 25$

Received: 2018-03-10, accepted: 2018-05-08. 
Pada pemetaan valuasi di atas, dikenal istilah value group dari $\nu$. Value group ini merupakan peta dari $K^{*}$ ke $G$ atau dilambangkan dengan $\nu\left(K^{*}\right)$ dimana, $K^{*}=K-\{0\}$. Perhatikan bahwa pemetaan $\nu$ dari $K^{*}$ ke $G$ merupakan homomorfisma grup. Oleh karena itu, value group merupakan subgrup dari $G$. Himpunan yang memuat semua unsur-unsur di $K$ yang nilai valuasinya lebih besar atau sama dengan 0 akan membentuk struktur berupa ring. Himpunan inilah yang disebut sebagai ring valuasi.

Selanjutnya jika diketahui sebarang ring valuasi $R$. Pada ring tersebut, terdapat pula pemetaan valuasi. Pemetaan valuasi ini merupakan pemetaan yang didefinisikan dari lapangan hasil bagi dari $R$, yaitu $K$ ke suatu grup terurut $G$ digabung dengan himpunan $\{\infty\}$. Grup terurut $G$ ini diperoleh dari hasil konstruksi yang melibatkan unsur-unsur unit di ring $R$. Unsur unit disini merupakan unsur yang memiliki invers terhadap perkalian di $R$.

Pada tulisan ini, akan dibahas mengenai ring valuasi diskrit. Terdapat banyak karakterisasi dari ring valuasi diskrit. Salah satunya adalah yang dinyatakan oleh Matsumura [2], yaitu, ring valuasi diskrit merupakan ring yang value group dari pemetaan valuasinya isomorfik (grup) dengan himpunan bilangan bulat.

\section{Metode Penelitian}

Penelitian ini merupakan penelitian studi literatur. Metodologi yang digunakan adalah dengan mengumpulkan bahan-bahan dari buku dan jurnal yang terkait dengan ring valuasi diskrit. Penulis mengembangkan sifat-sifat yang ada pada buku dan jurnal yang diperoleh. Selain itu, alur pembuktian ditulis dengan cara yang berbeda. Alur pembuktian tersebut dikaitkan dengan konsep barisan yang ada pada analisis real.

\section{Hasil dan Pembahasan}

3.1. Sifat-Sifat Ring. Untuk selanjutnya (kecuali terdapat keterangan lebih lanjut), dimisalkan bahwa $R$ merupakan ring valuasi diskrit dengan pemetaan valuasi $\nu$ dan $K$ merupakan lapangan hasil bagi dari $R$.

Seperti yang telah dikatakan bahwa ring valuasi erat kaitannya dengan adanya pemetaan valuasi. Oleh karena itu, dalam melihat unsur-unsur dari ideal maksimalnya, cukup dilihat nilai valuasi dari unsur tersebut. Perhatikan lemma berikut.

Lemma 3.1. Himpunan $M=\{x \in K \mid \nu(x)>0\}$ merupakan ideal maksimal dari $R$.

BukTi. Perhatikan bahwa $M \neq \emptyset$ karena $0 \in M$. Misalkan $x, y \in M$.

$$
\begin{aligned}
\nu(x+y) & \geq \min \{\nu(x), \nu(y)\} \\
& >0 .
\end{aligned}
$$

Jadi terbukti bahwa $(x+y) \in M$. Selanjutnya misalkan $r \in R$ sebarang. Perhatikan bahwa

$$
\begin{aligned}
& \nu(r x)=\underbrace{\nu(r)}_{\geq 0}+\underbrace{\nu(x)}_{>0} \\
& >0 \text {. }
\end{aligned}
$$

Jadi terbukti bahwa $r x \in M$.

Misalkan $M \subseteq I \subset R$ dimana $I$ merupakan ideal di $R$. Akan ditunjukkan bahwa $I=M$. Tulis $x$ sebagai sebarang unsur di $I$. Karena $x$ juga berada di $R$, maka $\nu(x) \geq 0$. Andaikan $\nu(x)=0$. Perhatikan bahwa

$$
\begin{aligned}
\nu(x) & =0 \\
\nu(x)-\nu(x) & =-\nu(x) \\
0 & =\nu\left(x^{-1}\right) .
\end{aligned}
$$

Berdasarkan persamaan 3, dapat disimpulkan bahwa $x$ merupakan unsur unit di $R$. Hal ini mengakibatkan kontradiksi, yaitu $I=R$. Jadi semua unsur di $I$ memiliki nilai valuasi yang lebih besar nol. Dengan demikian, $I=M$. 
Selain unsur dari ideal maksimal, dapat pula dilihat nilai valuasi dari unsur unit di $R$. Unsur unit disini merupakan unsur yang memiliki invers terhadap perkalian. Sifat dari unsur unit tersebut tertuang dalam lemma berikut.

Lemma 3.2. Unsur $x$ merupakan unsur unit di $R$ jika dan hanya jika $\nu(x)=0$.

Bukti. $(\Longrightarrow)$ Misalkan $x$ sebarang unsur unit di $R$. Artinya terdapat $x^{-1} \in R$. Perhatikan bahwa

$$
\begin{aligned}
\nu\left(x \cdot x^{-1}\right) & =\nu(x)+\nu\left(x^{-1}\right) \\
& =\nu(x)-\nu(x) \\
& =0 .
\end{aligned}
$$

Diperoleh

$$
\begin{aligned}
\nu\left(x \cdot x^{-1}\right) & =0 \\
\nu(x)+\nu\left(x^{-1}\right) & =0 \\
\underbrace{\nu(x)}_{\geq 0} & =-\underbrace{\nu\left(x^{-1}\right)}_{\geq 0} .
\end{aligned}
$$

Bilangan bulat non-negatif yang memenuhi persamaan di atas hanyalah 0. Jadi terbukti bahwa $\nu(x)=0$.

$(\Longleftarrow)$ Selanjutnya, misalkan $\nu(x)=0$ dimana $x \in R$. Perhatikan bahwa $x$ memiliki invers, yaitu $x^{-1}$ di $K$. Diperoleh bahwa

$$
\begin{aligned}
\nu\left(x \cdot x^{-1}\right) & =\nu(1) \\
\nu(x)+\nu\left(x^{-1}\right) & =0 \\
0+\nu\left(x^{-1}\right) & =0 \\
\nu\left(x^{-1}\right) & =0 .
\end{aligned}
$$

Karena $\nu\left(x^{-1}\right)=0$, maka $x^{-1}$ berada di $R$. Jadi $x$ merupakan unsur unit di $R$.

Dua sifat sebelumnya membahas mengenai nilai valuasi dari unsur-unsur di $R$. Unsurunsur dengan nilai valuasi positif merupakan unsur dari ideal maksimal. Sedangkan unsurunsur dengan nilai valuasi sama dengan nol merupakan unsur unit di $R$. Sekarang perhatikan $1 \in \mathbb{Z}$. Bilangan 1 memiliki keistimewaan di dalam himpunan bilangan bulat karena 1 merupakan suatu pembangun dari $\mathbb{Z}$. Apakah suatu unsur di $R$ dengan nilai valuasi yang sama dengan 1 juga memiliki keistimewaan di $R$ ? Jawaban dari pertanyaan disajikan dalam lemma berikut.

Lemma 3.3. Pada ring valuasi diskrit $R$, terdapat unsur non nilpotent.

BukTi. Diketahui bahwa $\nu\left(K^{*}\right)$ isomorfik dengan $\mathbb{Z}$. Oleh karena itu, terdapat $p \in K^{*}$ sehingga $\nu(p)=1$. Andaikan terdapat $m \in \mathbb{Z}_{>0}$ sehingga $p^{m}=0$. Perhatikan bahwa:

$$
\begin{aligned}
\nu\left(p^{m}\right) & =\nu(\underbrace{p \cdot p \cdot \ldots \cdot p}_{\text {sebanyak } m \text { suku }}) \\
\nu(0) & =\underbrace{\nu(p)+\nu(p)+\ldots+\nu(p)}_{\text {sebanyak } m \text { suku }} \\
\infty & =\underbrace{1+1+\ldots+1}_{\text {sebanyak } m \text { suku }} \\
\infty & =m .
\end{aligned}
$$

Persamaan 7 menimbulkan kontradiksi. Jadi tidak terdapat bilangan bulat positif $m$ sehingga $p^{m}=0$. Dengan demikian, $p$ merupakan unsur non nilpotent. 
Dalam proses pembuktian karakterisasi ring valuasi diskrit, terdapat konsep dari Jacobson Radical atau dilambangkan dengan $J(R)$. Jacobson Radical dari sebarang ring $R$ merupakan irisan dari seluruh ideal kanan maksimal dari $R$. Jacobson Radical juga merupakan irisan dari seluruh ideal kiri maksimal dari $R$ (Piotr, Askar [4]). Untuk mengetahui lebih jelas mengenai unsur-unsur di $R$ yang bagaimana yang termasuk dalam unsur di Jacobson Radical, perhatikan lemma berikut.

Lemma 3.4. $[2$, p.3] Misalkan $R$ merupakan sebarang ring. Jacobson radical dari $R$ adalah himpunan berikut:

$$
J(R)=\left\{x \in R \mid 1+R x R \subset R^{\times}\right\}
$$

dimana $R^{\times}$merupakan himpunan semua unsur unit di $R$.

Unsur dalam ideal maksimal dari ring valuasi diskrit $R$ dalam lemma sebelumnya merupakan unsur dengan nilai valuasi positif. Jika ditinjau lebih jauh, ternyata unsur dalam ideal maksimal tersebut juga dapat dinyatakan sebagai hasil kali dari suatu unsur di $R$ dengan suatu unsur non nilpotent di $R$. Pernyataan tersebut merupakan bunyi dari lemma berikut.

Lemma 3.5. Jika $M$ merupakan ideal maksimal dari $R$, maka $M=R p$ untuk suatu $p$ unsur non nilpotent di $R$.

Bukti. Berdasarkan lemma 3.3, terdapat unsur non nilpotent di $R$, yaitu $p$ dimana $\nu(p)=1$. Perhatikan bahwa jelas $R p \subseteq M$. Misalkan $0 \neq x \in M$ sebarang. Berdasarkan lemma 3.1, $\nu(x)=n$ untuk suatu $n \in \mathbb{Z}_{>0}$. Perhatikan bahwa:

$$
\begin{aligned}
\nu(x) & =n \\
& =\underbrace{1+1+\ldots+1}_{\text {sebanyak } n \text { suku }} \\
& =\underbrace{\nu(p)+\nu(p)+\ldots+\nu(p)}_{\text {sebanyak } n \text { suku }} \\
& =\nu\left(p^{n}\right) .
\end{aligned}
$$

Karena $\nu\left(K^{*}\right)$ isomorfik dengan $\mathbb{Z}$, maka $x=p^{n}=p^{n-1} \cdot p \in R p$. Ini berarti terbukti bahwa $M \subseteq R p$. Dengan demikian, $M=R p$.

Lemma 3.6. [3, p. 5009] Misalkan $R$ merupakan sebarang ring yang memenuhi ketiga kondisi berikut:

(1) $R$ merupakan ring lokal,

(2) $J(R)=p R=R p$ dimana $p$ merupakan unsur non nilpotent di $R$,

(3) $\bigcap_{n \geq 0}(J(R))^{n}=0$.

Misalkan pula $0 \neq a \in R$ dengan a merupakan unsur nonunit. Terdapat tunggal $m \in \mathbb{Z}_{>0}$ sehingga $a=r p^{m}$ dimana $r$ merupakan unsur unit di $R$.

Bukti. Berdasarkan lemma 3.1 dan lemma 3.2, $a \in M$ untuk suatu a unsur nonunit. Sedangkan berdasarkan lemma 3.5, diperoleh bahwa $a \in R p$. Oleh karena itu, terdapat $m \in \mathbb{Z}_{>0}$ sehingga $a \in R p^{m}$. Tulis $a=r p^{m}$ untuk suatu $r \in R$. Andaikan $r$ bukan merupakan unsur unit. Diperoleh bahwa $a \in R p^{n}$ untuk setiap $n \in \mathbb{Z}_{>0}$. Berdasarkan kondisi 3, diperoleh bahwa $a=0$. Hal ini menimbulkan kontradiksi dengan apa yang diketahui, yaitu $a \neq 0$. Jadi $r$ merupakan unsur unit. Andaikan $a=s p^{m+l}$ untuk suatu $l \in \mathbb{Z}_{>0}$ dan unsur unit $s$. Perhatikan bahwa:

$$
\begin{aligned}
r p^{m} & =s p^{m+l} \\
r p^{m}-s p^{m+l} & =0 \\
\left(r-s p^{l}\right) p^{m} & =0 \\
\left(1-s p^{l} r^{-1}\right) r p^{m} & =0 .
\end{aligned}
$$


Perhatikan bahwa berdasarkan kondisi 2, unsur $p^{l}$ berada di $J(R)$. Berdasarkan lemma 3.4, $\left(1-s p^{l} r^{-1}\right)$ merupakan unsur unit di $R$. Oleh karena itu, diperoleh bahwa $a=r p^{m}=0$. Hal ini menimbulkan kontradiksi dengan fakta bahwa $a \neq 0$. Jadi terbukti bahwa setiap unsur nonunit di $R$ dapat dituliskan secara tunggal dalam bentuk $r p^{m}$ dengan $r$ merupakan unsur unit dan $m \in \mathbb{Z}_{>0}$.

Dalam [3], ring valuasi diskrit pada dasarnya merupakan daerah integral. Akan tetapi, di dalam alur pembuktian karakterisasi ring valuasi diskrit dalam tulisan ini, tidak digunakan sifat komutatif dari ring $R$. Oleh sebab itu, dibutuhkan suatu sifat sebagai ganti dari sifat kekomutatifan dari ring $R$. Sifat tersebut dipaparkan dalam lemma berikut.

Lemma 3.7. Misalkan $R$ merupakan ring yang memenuhi ketiga kondisi pada lemma 3.6 dan misalkan pula $0 \neq x \in R$ merupakan unsur nonunit di $R$. Berlaku bahwa $x \in R p^{n}-R p^{n+1}$ jika dan hanya jika $x \in p^{n} R-p^{n+1} R$.

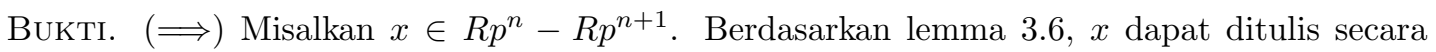
tunggal sebagai $x=u p^{n}$, dengan $u$ merupakan unit di $R$. Perhatikan bahwa:

$$
\begin{aligned}
x & =\underbrace{u p}_{\in R p=p R}\left(p^{n-1}\right) \\
& =\left(p u_{1}\right) p^{n-1} .
\end{aligned}
$$

Andaikan $u_{1}$ merupakan unsur nonunit di $R$. Berdasarkan lemma 3.1 dan 3.2, $u_{1}$ merupakan unsur di $R p=p R$. Tulis $u_{1}=r p$. Diperoleh bahwa

$$
\begin{aligned}
x & =\left(p u_{1}\right) p^{n-1} \\
& =p(r p) p^{n-1} \\
& =\underbrace{(p r)}_{\in p R=R p} p^{n} \\
& =r^{\prime} p \cdot p^{n} \\
& =\underbrace{r^{\prime} p^{n+1}}_{\in R p^{n+1}} .
\end{aligned}
$$

Persamaan terakhir menimbulkan kontradiksi terhadap fakta bahwa $x \notin R p^{n+1}$. Jadi $u_{1}$ merupakan unsur unit di $R$. Dengan cara yang serupa, diperoleh bahwa $x=p^{n} v$ dengan $v \in R$. Selanjutnya akan ditunjukkan bahwa $x \notin p^{n+1} R$. Andaikan $x \in p^{n+1} R$. Tulis $x=p^{n+1} r$ dengan $r \in R$. Karena $R p=p R$, maka diperoleh $x=s p^{n+1} \in R p^{n+1}$. Hal ini menimbulkan kontradiksi dengan fakta bahwa $x \notin R p^{n+1}$. Jadi $x \notin p^{n+1} R$.

$(\Longleftarrow)$ Misalkan $x \in p^{n} R-p^{n+1} R$. Tulis $x=p^{n} r$ untuk suatu $r \in R$. Perhatikan bahwa:

$$
\begin{aligned}
x & =p^{n} r \\
& =p^{n-1} \underbrace{(p r)}_{\in p R=R p} \\
& =p^{n-1} s_{1} p \\
& \vdots \\
& =s_{n} p^{n} \in R p^{n} .
\end{aligned}
$$

Andaikan $x \in R p^{n+1}$. Dengan menggunakan fakta bahwa $R p=p R$, maka diperoleh $x \in p^{n+1} R$. Hal ini menimbulkan kontradiksi. Dengan demikian, terbukti bahwa $x \in R p^{n}-R p^{n+1}$.

3.2. Barisan Bilangan Real. Dalam alur pembuktian karakterisasi ring valuasi diskrit di dalam tulisan ini, terdapat suatu barisan yang terbentuk sebagai akibat dari adanya pemetaan valuasi. Oleh karena itu, alur pembuktian tersebut dikaitkan dengan konsep barisan bilangan real yang terdapat dalam analisis real. 
Definisi 3.8. [1, Definisi 3.2.1] Barisan $\left(x_{n}\right)$ dari bilangan real dikatakan terbatas jika terdapat bilangan real $M>0$ sehingga $\left|x_{n}\right| \leq M$ untuk setiap $n \in \mathbb{N}$.

Salah satu barisan bilangan real yang pasti terbatas adalah barisan yang konvergen (Bartle, R.G., Sherbert, D.R., [1]). Pernyataan tersebut merupakan bunyi dari lemma berikut.

Lemma 3.9. [1, Teorema 3.2.2] Setiap barisan bilangan real yang konvergen pasti terbatas.

Contoh 3.10. Barisan $\left(a_{n}\right)$ dimana $a_{n}=\frac{1}{n}$ merupakan barisan yang konvergen ke 0 . Barisan ini merupakan barisan terbatas karena terdapat $M=1 \in \mathbb{R}$ sehingga $\left|a_{n}\right| \leq 1$ untuk setiap $n \in \mathbb{N}$.

Berikut karakterisasi ring valuasi diskrit yang akan dibuktikan ke-ekivalenan-nya.

Teorema 3.11. Suatu ring $R$ merupakan ring valuasi diskrit jika dan hanya jika memenuhi ketiga kondisi berikut:

(1) $R$ merupakan ring lokal,

(2) $J(R)=p R=R p$ dimana $p$ merupakan unsur non nilpotent di $R$,

(3) $\bigcap_{n \geq 0} R p^{n}=0=\bigcap_{n \geq 0} p^{n} R$.

Bukti. ( $\Longrightarrow$ ) Misalkan $R$ merupakan ring valuasi diskrit dengan pemetaan valuasi $\nu$. Akan ditunjukkan bahwa $R$ merupakan ring lokal. Berdasarkan lemma 3.1, $M$ merupakan ideal maksimal dari $R$. Misalkan terdapat ideal maksimal $I$ dari $R$ dan $0 \neq x \in I$ sebarang. Karena $I$ merupakan ideal, maka unsur $x$ merupakan unsur nonunit. Ini artinya $\nu(x)>0$. Jadi terbukti bahwa ideal maksimal di $R$ tunggal. Dengan demikian, $R$ merupakan ring lokal.

Selanjutnya akan ditunjukkan bahwa $J(R)=R p=p R$ untuk suatu unsur non nilpotent $p$. Telah dibuktikan bahwa ideal maksimal dari $R$ bersifat tunggal. Oleh karena itu diperoleh bahwa $J(R)=M$ dengan $M$ merupakan ideal maksimal dari $R$. Berdasarkan lemma 3.5, terbukti bahwa $J(R)=M=R p$.

Selanjutnya akan ditunjukkan bahwa $\bigcap_{n \geq 0}\left(R p^{n}\right)=0$. Perhatikan bahwa jelas $0 \subseteq$ $\bigcap_{n>0}\left(R p^{n}\right)$. Misalkan $x \in \bigcap_{n>0}\left(R p^{n}\right)$ sebarang. Artinya $x=r_{n} p^{n}$ untuk setiap $n \in \mathbb{Z}_{\geq 0}, r_{n} \in$ $R$. Diperoleh barisan:

$$
\begin{aligned}
\nu(x) & =\nu\left(r_{1}\right)+\nu(p) \\
& =\nu\left(r_{1}\right)+1 \\
\nu(x) & =\nu\left(r_{2}\right)+\nu(p) \\
& =\nu\left(r_{2}\right)+2 \\
\nu(x) & =\nu\left(r_{3}\right)+\nu(p) \\
& =\nu\left(r_{3}\right)+3 \\
: & \\
\nu(x) & =\nu\left(r_{n}\right)+\nu(p) \\
& =\nu\left(r_{n}\right)+n .
\end{aligned}
$$

Perhatikan bahwa:

$$
\nu(x)=\lim _{n \longrightarrow \infty}\left(\nu\left(r_{n}\right)+n\right)
$$

dimana $\nu\left(r_{n}\right) \geq 0$. Andaikan barisan 13 konvergen. Berdasarkan lemma 3.9, barisan $\left(\nu\left(r_{n}\right)+n\right)$ terbatas. Berdasarkan lemma 3.8, terdapat $M>0$ sehingga berlaku

$$
\left|\nu\left(r_{n}\right)+n\right| \leq M, \forall n \in \mathbb{N}
$$

Perhatikan bahwa:

$$
\begin{aligned}
n & =|n| \\
& \leq\left|\nu\left(r_{n}\right)+n\right| \\
& \leq M
\end{aligned}
$$


untuk setiap $n \in \mathbb{N}$. Hal ini juga berlaku untuk $m \in \mathbb{N}$ dimana $m \geq M+2$. Oleh karena itu diperoleh bahwa $m \leq M+2 \leq M$. Hal ini merupakan kontradiksi. Jadi $\nu(x)=\lim _{n \longrightarrow \infty} \nu(x)=$ $\lim _{n \longrightarrow \infty}\left(\nu\left(r_{n}\right)+n\right)=\infty$. Ini artinya, $x=0$.

$(\Longleftarrow)$ Misalkan $R$ memenuhi ketiga kondisi di atas. Akan ditunjukkan bahwa $R$ merupakan ring valuasi diskrit. Untuk membuktikannya, akan ditunjukkan bahwa terdapat pemetaan valuasi $\nu$ dari lapangan hasil bagi dari $R$ ke grup $(\mathbb{Z},+)$. Misalkan $a \in R$ sebarang.

(1) Jika $a=0$, maka definisikan $\nu(a)=\infty$.

(2) Jika $a$ merupakan unsur unit di $R$, maka definisikan $\nu(a)=0$.

(3) Sekarang misalkan $a$ merupakan unsur nonunit di $R$. Perhatikan ideal $R a$. Ideal ini pasti termuat dalam suatu ideal maksimal. Berdasarkan kondisi 1, ideal maksimal dari $R$ bersifat tunggal. Misalkan ideal tersebut adalah $M$. Berdasarkan kondisi 2, diperoleh bahwa $M=R p$. Oleh karena itu, didapat $a \in R p$. Dengan demikian,terdapat bilangan bulat positif terkecil $m$ sehingga $a \in R p^{m}$. Definisikan $\nu(a)=m$.

Dari pendefinisian di atas, jelas bahwa $\nu$ merupakan pemetaan. Misalkan $a, b \in R$ sebarang dengan $a, b \neq 0$.

(1) Jika $a, b$ masing-masing unit di $R$, maka $(a b)$ unit di $R$. Dengan demikian, diperoleh bahwa $\nu(a b)=0=0+0=\nu(a)+\nu(b)$.

(2) Jika $a$ unit di $R$ dan $b$ nonunit di $R$, maka $(a b)$ nonunit di $R$. Perhatikan bahwa terdapat bilangan bulat positif terkecil $m$ sehingga $(a b) \in R p^{m}$. Tulis $(a b)=r p^{m}$. Jika $m$ bukan merupakan bilangan bulat positif terkecil sehingga $b \in R p^{m}$, maka $m$ juga bukan merupakan bilangan bulat positif terkecil sehingga $(a b) \in R p^{m}$. Perhatikan bahwa

$$
\begin{aligned}
\nu(a b) & =m \\
& =0+m \\
& =\nu(a)+\nu(b) .
\end{aligned}
$$

(3) Jika masing-masing $a$ nonunit dan $b$ unit di $R$, maka $(a b)$ merupakan unsur nonunit di $R$. Perhatikan bahwa terdapat bilangan bulat positif terkecil $m$ sehingga $(a b) \in R p^{m}$. Tulis $(a b)=r p^{m}$ untuk suatu $r \in R$. Perhatikan bahwa:

$$
\begin{aligned}
a & =r p^{m} b^{-1} \\
& =r p^{m-1} \cdot \underbrace{(p b)}_{\in p R=R p} \\
& =r p^{m-1}\left(s_{1} p\right) \\
& =r p^{m-2} \cdot \underbrace{\left(p s_{1}\right)}_{\in p R=R p} \cdot p \\
& : \\
& =\underbrace{\left(r s_{m}\right) p^{m}}_{\in R p^{m}} \cdot
\end{aligned}
$$

Jika $m$ bukan merupakan bilangan bulat positif terkecil sehingga $a \in R p^{m}$, maka $m$ juga bukan merupakan bilangan bulat positif terkecil sehingga $(a b) \in R p^{m}$. Dengan demikian, diperoleh bahwa

$$
\begin{aligned}
\nu(a b) & =m \\
& =m+0 \\
& =\nu(a)+\nu(b) .
\end{aligned}
$$

(4) Jika $a, b$ masing-masing merupakan nonunit di $R$. Ini artinya $(a b)$ merupakan nonunit di $R$. Dengan cara yang serupa seperti kasus 3, diperoleh bahwa $\nu(a b)=\nu(a)+\nu(b)$.

Selanjutnya, akan ditunjukkan bahwa $\nu(a+b) \geq \min \{\nu(a), \nu(b)\}$. Akan dibagi menjadi beberapa kasus dalam pembuktiannya. 
(1) Misalkan $a, b$ keduanya merupakan unsur unit di $R$. Ini artinya, $\nu(a)=0$ dan $\nu(b)=0$. Karena $(a+b) \in R$, maka berdasarkan definisi pemetaan $\nu$, jelas bahwa $\nu(a+b) \geq 0=$ $\min \{\nu(a), \nu(b)\}$.

(2) Misalkan $a$ unit dan $b$ nonunit di $R$. Diperoleh $\min \{\nu(a), \nu(b)\}=\nu(a)=0$. Karena $(a+b) \in R$, maka berdasarkan definisi pemetaan $\nu, \nu(a+b) \geq 0=\min \{\nu(a), \nu(b)\}$.

(3) Misalkan $a, b$ kedua-duanya merupakan unsur nonunit di $R$ dan $\nu(a) \geq \nu(b)$. Akan ditunjukkan bahwa $\nu(a+b) \geq \nu(b)$. Andaikan $\nu(a+b)<\nu(b)$. Diperoleh bahwa

$$
\begin{aligned}
\nu(b)-\nu(a+b) & >0 \\
\nu\left(b(a+b)^{-1}\right) & >0 .
\end{aligned}
$$

Berdasarkan definisi pemetaan $\nu$, terdapat unsur nonunit $r$ sehingga $b(a+b)^{-1}=r$. Perhatikan bahwa

$$
\begin{aligned}
b & =r(a+b) \\
& =r a+r b \\
b-r b & =r a \\
(1-r) b & =r a .
\end{aligned}
$$

Perhatikan bahwa ideal $R r$ pasti termuat dalam suatu ideal maksimal. Berdasarkan kondisi 1, ideal maksimal dari $R$ tunggal. Oleh karena itu, berdasarkan kondisi 2, ideal maksimalnya adalah $R p$. Jadi $r \in R p=J(R)$. Berdasarkan lemma 3.4, maka $(1-r)$ merupakan unsur unit di $R$. Diperoleh $b=(1-r)^{-1} r a$. Perhatikan bahwa

$$
\begin{aligned}
\nu(a+b) & =\nu\left(a+(1-r)^{-1} r a\right) \\
& =\nu\left(\left(1+(1-r)^{-1} r\right) a\right) .
\end{aligned}
$$

Karena $r \in J(R)$, maka $\left(1+(1-r)^{-1} r\right)$ unit di $R$. Dengan demikian, diperoleh bahwa

$$
\begin{aligned}
\nu(a+b) & =\nu\left(\left(1+(1-r)^{-1} r\right)\right)+\nu(a) \\
& =0+\nu(a) \\
& =\nu(a) \\
& \geq \nu(b) .
\end{aligned}
$$

Persamaan 23 menimbulkan kontradiksi dengan $\nu(a+b)<\nu(b)$. Jadi, $\nu(a+b) \geq \nu(b)=$ $\min \{\nu(a), \nu(b)\}$.

Pemetaan $\nu$ ini dapat diperluas menjadi pemetaan dari lapangan hasil bagi dari $R$, yaitu $K$ ke $\mathbb{Z} \cup\{\infty\}$ dengan pendefinisian $\nu\left(\frac{a}{b}\right)=\nu(a)-\nu(b)$ dimana $\left(\frac{a}{b}\right) \in K$. Perluasan pemetaan ini juga merupakan pemetaan valuasi. Hal ini dapat dibuktikan dengan mudah menggunakan fakta bahwa $\nu$ dari $R$ ke $\mathbb{Z} \cup\{\infty\}$ merupakan pemetaan valuasi.

\section{Simpulan}

Berdasarkan teorema 3.11 terbukti bahwa definisi yang dinyatakan oleh Matsumura [2] dan Piotr, Askar [3] ekivalen. Dengan kata lain karakterisasi tersebut dapat dinyatakan sebagai berikut.

Ring $R$ disebut ring valuasi diskrit jika memenuhi salah satu dari dua kondisi berikut.

(1) Value group dari pemetaan valuasinya isomorfik (grup) terhadap $\mathbb{Z}$.

(2) Ring $R$ memenuhi ketiga pernyataan berikut:

(a) $R$ merupakan ring lokal,

(b) $J(R)=p R=R p$ dimana $p$ merupakan unsur non nilpotent di $R$,

(c) $\bigcap_{n \geq 0} R p^{n}=0=\bigcap_{n \geq 0} p^{n} R$. 


\section{DAFTAR Pustaka}

[1] Bartle, R.G., Sherbert, D.R., 2000, Introduction to real Analysis, John Wiley and Sons, Inc, United State of America.

[2] Matsumura, Hideyuki, Commutative Ring Theory, Cambridge University Press.

[3] Piotr., K., Askar., A.T., 2007, Modules Over Discrete Valuation Domains I, Journal of Mathematics Science, Volume 145, No.4, 5008-5048. 